\title{
IDENTIFICATION AND CHARACTERISTICS OF BIOLOGICAL AGENTS IN WORK ENVIRONMENT OF MEDICAL EMERGENCY SERVICES IN SELECTED AMBULANCES
}

AGATA BIELAWSKA-DRÓZD ${ }^{1}$, PIOTR CIEŚLIK, BOŻENA WLIZLO-SKOWRONEK, IZABELA WINNICKA², LESZEK KUBIAK², JOLANTA JAROSZUK-ŚCISEL ${ }^{3}$, DARIA DEPCZYŃSKA², JUSTYNA BOHACZ4, TERESA KORNIELOWICZ-KOWALSKA ${ }^{4}$, EWA SKOPIŃSKA-RÓŻEWSKA ${ }^{2,5}$, and JANUSZ KOCIK²

${ }^{1}$ Military Institute of Hygiene and Epidemiology, Puławy, Poland

Biological Threats Identification and Countermeasure Center

${ }^{2}$ Military Institute of Hygiene and Epidemiology, Warszawa, Poland

Laboratory of Epidemiology

${ }^{3}$ Maria Curie-Skłodowska University, Lublin, Poland

Faculty of Biology and Biotechnology, Department of Environmental Microbiology

${ }^{4}$ University of Life Sciences in Lublin, Lublin, Poland

Faculty of Agrobioengineering, Department of Environmental Microbiology, Laboratory of Mycology

${ }^{5}$ Medical University of Warsaw, Warszawa, Poland

Pathology Department, Biostructure Centre

\begin{abstract}
Objectives: Assessment of microbial air quality and surface contamination in ambulances and administration offices as a control place without occupational exposure to biological agents; based on quantitative and qualitative analysis of bacteria, yeasts and filamentous fungi found in collected samples. Material and Methods: The sampling was done by wet cyclone technology using the $\mathrm{Co}$ riolis recon apparatus, imprint and swab methods, respectively. In total, 280 samples from 28 ambulances and 10 offices in Warszawa were tested. Data was analyzed using Shapiro-Wilk normality test, Kruskal-Wallis test with $\alpha=0.05$. P value $\leq 0.05$ was considered as significant. Results: The levels of air contamination were from 0 to $2.3 \times 10^{1}$ colony-forming unit $(\mathrm{CFU}) / \mathrm{m}^{3}$ for bacteria and for yeast and filamentous fungi were from 0 to $1.8 \times 10^{1} \mathrm{CFU} / \mathrm{m}^{3}$. The assessment of office space air samples has shown the following numbers of microorganisms: bacteria from $3.0 \times 10^{1}$ to $4.2 \times 10^{1} \mathrm{CFU} / \mathrm{m}^{3}$ and yeast and filamentous fungi from 0 to $1.9 \times 10^{1} \mathrm{CFU} / \mathrm{m}^{3}$. For surface contamination the mean bacterial count in ambulances has been between $1.0 \times 10^{1}$ and $1.3 \times 10^{2} \mathrm{CFU} / 25 \mathrm{~cm}^{2}$ and in offices - between $1.1 \times 10^{1}$ and $8.5 \times 10^{1} \mathrm{CFU} / 25 \mathrm{~cm}^{2}$. Mean fungal count has reached the level from $2.8 \times 10^{0}$ to $4.2 \times 10^{1} \mathrm{CFU} / 25 \mathrm{~cm}^{2}$ in ambulances and $1.3 \times 10^{1}$ to $5.8 \times 10^{1} \mathrm{CFU} / 25 \mathrm{~cm}^{2}$ in offices. The qualitative analysis has revealed the presence of Acinetobacter spp. (surfaces), coagulase - negative Staphylococci (air and surfaces), Aspergillus and Penicillium genera (air and surfaces). Conclusions: The study has revealed a satisfactory microbiological quantity of analyzed air and surface samples in both study and control environments. However, the presence of potentially pathogenic microorganisms in the air and on surfaces in ambulances may endanger the medical emergency staff and patients with infection. Disinfection and cleaning techniques therefore should be constantly developed and implemented. Int J Occup Med Environ Health 2017;30(4):617-627
\end{abstract}

Key words:

Bacteria, Fungi, Work environment, Harmful biological agents, Antimicrobial resistance, Ambulances

Received: October 7, 2015. Accepted: June 28, 2016.

Corresponding author: A. Bielawska-Drózd, Military Institute of Hygiene and Epidemiology, Biological Threats Identification and Countermeasure Center, Lubelska 2, 24-100 Puławy, Poland (e-mail: abielawska@wihe.pulawy.pl). 


\section{INTRODUCTION}

Risk assessment of the workplace microbiological contamination informs employers and workers about existing biohazards, allows determination of health safety and workplace hygiene of paramedics, and thus implies the necessity of protection against harmful biological agents.

While monitoring the microbiological status of healthcare institutions, e.g., hospitals has become routine [1-5], the analysis of microbiological contamination of ambulances is not subject to specific supervision. According to the 2009 State Sanitary Inspection that assessed the overall state of ambulances, $5.3 \%$ out of the 375 institutions that provided the records did not meet the sanitary criteria. This resulted primarily from deficiency of sanitary equipment, contamination of walls, ceilings and sanitation instruments and mismanagement of medical waste [6]. Moreover, in the 2010 report in 29 (10.5\%) out of 277 inspected ambulances inadequate sanitary conditions were found. In most cases the failures also resulted from deficiencies in sanitary equipment [7]. In 2011, the observations resembled those from 2009, where in the case of 18 (6.2\%) out of 291 Ambulance Services checked, defective sanitary engineering was found [7].

The most frequently found neglect arose from damaged interior surfaces, mainly floors and walls, which limited the capacity to perform effective disinfection of the ambulance space. In addition, failures were observed in complying with the medical facility mandatory procedures concerning washing and disinfection of hands, tools and medical equipment as well as small and hard to reach surfaces (air ventilation grating, medical equipment buttons, etc.) [6-8]. Moreover, the mobile nature of ambulance work promotes acceleration of corrosion processes and adhesion and growth of bacteria and; the latter is amplified by the usage of strong disinfectants [9]. Residual potential infection resulting from the bacterial growth may accumulate and persist in the microenvironment of an ambulance and thus be available for transmission to a new host [10]. According to Alves and
Bissell [10], a number of objects in the health care setting carry infectious bacteria: scissors, ballpoint pens, stethoscopes, coats, adhesive tapes, computer keyboards, water faucets or pagers or cell phones, air vent grates. It is known that presence of bacteria on these objects contributes to new infections for patients. On the other hand, a patient may also transmit infectious microorganisms (opportunistic or pathogenic) by coughing, vomiting, excreting, urinating in an ambulance during transport [10].

Therefore, the sanitary and hygienic status of ambulances requires assessments of the status of microbiological contamination. Persistence of high levels of contamination may result in microbial transmission from patients to medical personnel and to other patients. A careful analysis of microbial quantity and identification of potentially pathogenic agents may determine occupational risks of emergency medical services.

\section{Objective}

Assessment of microbial air quality and surface contamination in ambulances and office spaces without occupational exposure to biological agents; based on quantitative and qualitative analysis of bacteria, yeast and filamentous fungi found in collected samples.

\section{MATERIAL AND METHODS}

\section{Sampling, culturing,} quantitative and qualitative analysis

The bioaerosol and work surface sampling was done by wet technology, imprint and swab methods, respectively. The sampling was carried out during winter period in ambulances and office buildings without air conditions. The sampling of work surfaces was done by swab and imprint methods; air samples were collected by means of the cyclone wet technology method. In total, 280 samples were collected from 28 ambulances and 10 offices in Warszawa. The material for analysis from one examined workplace was gathered according to the following scheme: 1 air 
sample, 9 surface samples included 4 swabs (door handles, medical instrument buttons, ballpoint pens and air conditioner/ventilation grate) and 5 imprints (3 for bacteria, 2 for fungi included floors, walls, couches/tables). Similar sampling was used in the offices (10 workplaces) as a control not exposed to harmful biological agents.

Air samples were collected with the assistance of a Coriolis Recon apparatus (Bertin, France) placed on the high of $1.5 \mathrm{~m}$ which collects biological particles from 0.5$10.0 \mu \mathrm{m}$ in a liquid sample (volume $25 \mathrm{ml}$ ) at a flow rate of $6 \mathrm{~m}^{3}$ for $10 \mathrm{~min}$. The liquid material was filtered through $0.22 \mu \mathrm{m}$ filter (Merck Millipore, USA) using a Vacuum Pump P504 Millipore apparatus (Merck Millipore, USA). In the next step, the filter was placed onto the surface of the agar medium with 5\% sheep blood (Columbia Agar, Graso Biotech, Poland) and Sabouraud medium (Sabouroud Dextrose Agar, Graso Biotech, Poland). The culture plates were incubated for $24 \mathrm{~h}$, respectively, at $37^{\circ} \mathrm{C}$ followed by 3 days at $22^{\circ} \mathrm{C}$ for the bacteria and for $96 \mathrm{~h}$ at $28^{\circ} \mathrm{C}$ for the fungi. Next the number of bacterial and fungal colonies were counted and recalculated as colony forming units per $\mathrm{m}^{3}\left(\mathrm{CFU} / \mathrm{m}^{3}\right)$.

The biological material from irregular or hard to access surfaces (doorknobs, air conditioning units) was collected by swabbing, using wet cotton swabs placed in sterile saline solution. Flat work surfaces were sampled using: Count-Tact $^{\circledR}$ 3P ${ }^{\mathrm{TM}}$ Agar - CT3P (bioMérieux, France) for bacteria and Count-Tact ${ }^{\circledR}$ CTSI (bioMérieux, France) for yeasts and filamentous fungi determination, respectively. In order to ensure reproducibility of the collection conditions, a special applicator was used (Count-Tact ${ }^{\circledR}$ Applicator, bioMérieux, France). The biological material collected on Count-Tact plates (CT3P, CTSI) was culturing according to the manufacturer's recommendations (bioMérieux, France): 3 days at $30^{\circ} \mathrm{C} \pm 1^{\circ} \mathrm{C}$ (CT3P for bacteria) and 5 days at $22.5^{\circ} \mathrm{C} \pm 2.5^{\circ} \mathrm{C}$ (CTSI for fungi). Material from swabs was transferred onto agar medium with 5\% sheep blood (Columbia Agar, Graso Biotech,
Poland) and Sabouraud medium (Sabouraud Dextrose Agar, Graso Biotech, Poland). Biological material was incubated at $37^{\circ} \mathrm{C}$ for 1 day followed by 3 days at $22^{\circ} \mathrm{C}$ for bacteria and at $28^{\circ} \mathrm{C}$ for 5 to 7 days for fungi. Afterwards, the bacterial and fungal colonies were counted and calculated as $\mathrm{CFU} / 25 \mathrm{~cm}^{2}$.

Subsequently, the microbial isolates on respective agar media were classified at the genus and/or species using generally accepted diagnostic procedures. Identification of bacteria strains and testing their antibiotic susceptibility was carried out using an automated system Vitek2 Compact system (bioMérieux, France) following the manufacturer's instructions.

Species identification was carried out using the appropriate bar-coded cards for Gram-negative (GN), Gram-positive (GP) and anaerobic bacteria (ANC) (bioMérieux, France); suitable antibiogram cards were also used for determining isolates antibiotic susceptibility: AST-N258 (amikacin, amoxicillin/clav. acid, ampicllin, cefepime, cefotaxime, cefalexsin, ceftazidime, cefuroxime, ciprofloxacin, ertapenem, gentamicin, imipenem, nitrofurantoin, norfloxacin, piperacillin/tazobactam, trimethoprim/ sulfametoxazol), AST-N260 (amikacin, ampicylin/sulbactam, aztreonam, cefepime, cetazidime, cirpfoploxacin, colistin, gentamicin, imipenem, levofloxacin, meropenem, piperacillin, piperacillin/tazobactam, netilmycina, ticarcillin/clav. acid, tobramycin, trimethoprim/sulfametoxazol), AST-GP67 (ampicillin, benzylopenicillin, cefoxitin screen, ciprofloxacin, clindamycin, erythromycin, gentamicin, inducible clindamycin resistance, levofloxacin, linezolid, moxifloxacin, nitrofuratoin, oxacillin, quinopristin/dalfopristin, rifampicin, tetracycline, trimethoprim/sulfametoxazol, vancomycin) (bioMérieux, France).

Phenotypic methods were used for confirming specific antimicrobial resistance (disc diffusion method). Interpretation of results was based on the European Committee on Antimicrobial Susceptibility Testing (EUCAST) 
recommendation [11]. The following strains were used as the control references: Escherichia coli ATCC 25922, Enterococcus faecalis ATCC 29212, Staphylococcus aureus ATCC 29213, Pseudomonas aeruginosa ATCC 27853, Klebsiella pneumoniae ATCC 700603, Streptococcus pneumoniae ATCC 49619.

The identification of fungi was carried out in microcultures on potato dextrose agar (PDA) medium and was based on the morphological characteristics of the mycelium, e.g., the type of filaments and reproductive structure. Classification of genera and species of the isolated fungi was carried out according to the monographs of Domsch et al. [12], Barnett and Hunter [13] using a microscope Olympus BX-41 with a digital camera and software CVIII4 Cell-A. In accordance with the latest nomenclature currently in use the species name of the fungi have been introduced [14].

\section{RESULTS}

The microbial air and surface contamination in ambulances and administrative offices is shown in the Table 1.

In terms of the air quality assessment, most of isolated bacteria in ambulances $(8.4 \%)$ were coagulase-negative Staphylococci (CoNS) (Staphylococcus hominis (methicillin-resistant coagulase-negative Staphylococci-MRCNS) $2.8 \%$, Staphylococcus warnerii - 2.8\%, Staphylococcus capitis - 2.8\%). Moreover, Bacillus spp., Sphingomonas paucimobilis, Kocuria roseae, Rhizobium spp., Serratia plymuthica, Globicatella sulfidifaciens, Leclerica adecarboxylata and Aerococcus viridans were identified. There were no potentially pathogenic bacteria in indoor office air (Table 2).

In microbiological quality of imprint samples from ambulances, $5.6 \%$ of potentially pathogens were found. Most of them belong to Acinetobacter baumanii cplx. $-0.9 \%$, A r radioresistens $-0.9 \%$, methicillin-resistant S. aureus (MRSA) (alert-patogen) $-0.95 \%$, S. sciuri $-0.95 \%$, S. warnerii $0.95 \%$, S. xylosus $-0.95 \%$. In offices $14.3 \%$ microorganisms include non-fermentive Gram-negative bacilli (NFGNB): Acinetobacter lwofii - 11.4\%, A. baumanii cplx. $-2.9 \%$, and $8.56 \%$ - Staphylococcus spp. S. hominis - $2.86 \%$, Staphylococcus haemolyticus $-2.86 \%$, S. warnerii $-2.86 \%$. Main species of culturable bacteria identified from swabs in ambulances were $A$. heamolyticus - $0.8 \%, A$. lwoffi $0.8 \%$, Micrococcus luteus $-0.8 \%$, S. warneri $-1.6 \%$, S. saprophyticus $-0.8 \%$, S. heamolyticus $-0.8 \%$ and S. epidermidis $-0.8 \%$. In offices $18.5 \%$ potentially pathogenic bacteria included mainly coagulase-negative Staphylococci $(\mathrm{CoNS})-33.3 \%$. Alert pathogens were not detected (Table 2).

In the distribution analysis, the proportion of individual fungal groups in relation to total mycobiota isolated from the indoor air and surfaces was similar and showed $92 \%$ and $94 \%$ of filamentous fungi and $8 \%$ and $6 \%$ of yeasts in ambulances and offices, respectively.

The mycological analysis of air samples present in ambulances as well as in offices revealed similar distribution of fungi: Aspergillus spp. (25\%), A. versicolor (12.5\%), Penicillium spp. (12.5\%), P. expansum (12.5\%), P. citrinum (12.5\%) and Trichoderma koningii, Chaetomium globosum and Ulocladium atrum (37.5\%). As far as imprints and swab samples from ambulances as well from offices are concerned, the quality assessment results mainly revealed the presence of Aspergillus (42\%) and Penicillium (42\%) genera, widely thought of as toxin-producing. The isolates included the following species in ambulances: A. niger (18\%), A. fumigatus (9\%), Aspergillus spp. (18\%), P. expansum (27\%), Penicillium spp. (18\%) and T. koningii (9\%), and in offices: A. niger (6.6\%), A. fumigatus (6.6\%), A. versicolor (6.6\%), Aspergillus spp. (33\%), P. expansum (25\%), Penicillium spp. (25\%) and T. koningii (6.6\%). These species were found on surface environments. However, A. niger, A. fumigatus and P. expansum were mainly found in ambulances and office ventilation systems and on office computer keyboards. 

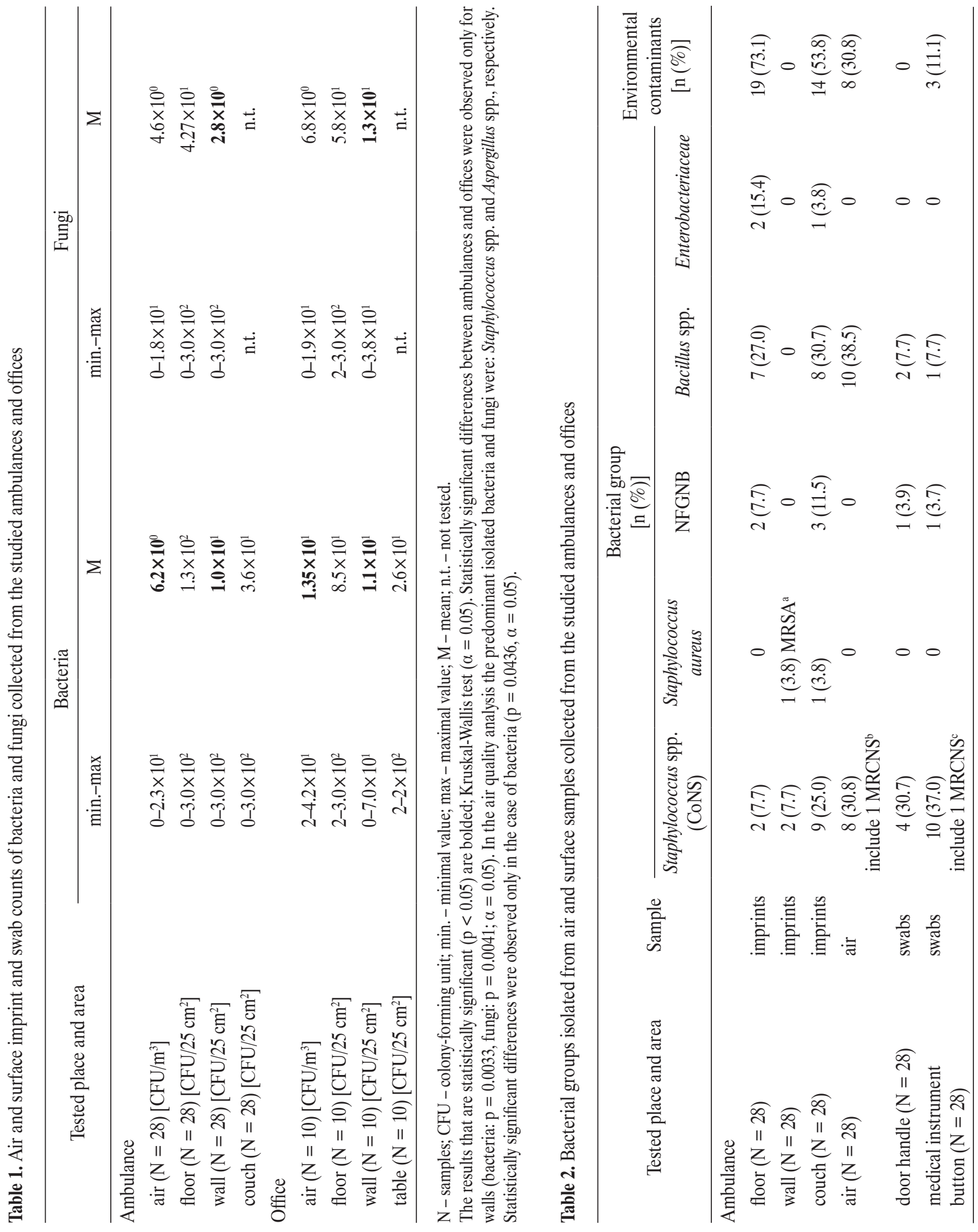


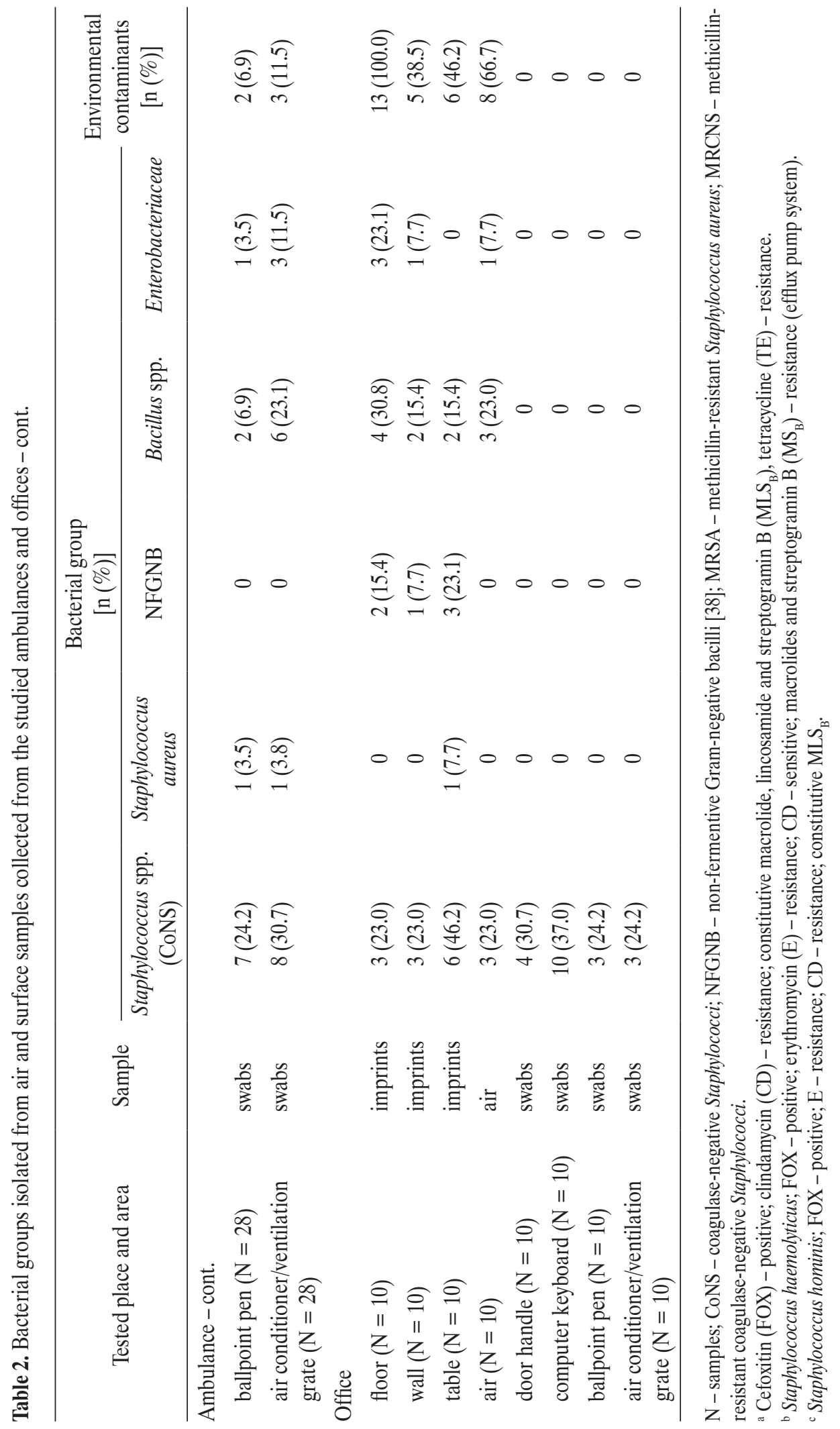




\section{DISCUSSION}

The conditions in ambulances may increase the risk of transmission among patient, to the healthcare personnel and the environment. Particularly air and surfaces of surrounding areas may be a source of contamination [15-17]. The study of microbial counts in indoor air samples collected from ambulances found relatively low level (mean $\left.(\mathrm{M})=6.2 \times 10^{0} \mathrm{CFU} / \mathrm{m}^{3}\right)$. Moreover, the values were lower in comparison to offices $\left(\mathrm{M}=1.36 \times 10^{1} \mathrm{CFU} / \mathrm{m}^{3}\right)$. The levels of yeast and filamentous fungi in the air samples also showed lower values than in office spaces. These microbiological levels contrast with the results of Luksamijarulkul et al. [18] where the bacterial and fungal counts in ambulance air showed the presence of several hundreds of colony forming units in $1 \mathrm{~m}^{3} ; 3.18 \times 10^{2}-4.85 \times$ $10^{2} \mathrm{CFU} / \mathrm{m}^{3}$ for bacteria and $5.22 \times 10^{2}-5.81 \times 10^{2} \mathrm{CFU} / \mathrm{m}^{3}$ for yeast and filamentous fungi.

The quantity of fungi in the air of office demonstrates a satisfying level from $3.0 \times 10^{0}$ to $4.2 \times 10^{1} \mathrm{CFU} / \mathrm{m}^{3}$ at the mean value $6.8 \times 10^{0} \mathrm{CFU} / \mathrm{m}^{3}$. It may be explained by good quality indoor air (the humidity above $50 \%$, no indications of moisture, no smell of mildew). Similar values were found by other researchers; while inspecting offices with evident traces of moisture facilitating to fungal growth, Buczyńska et al. received values 10 times higher $\left(2.7 \times 10^{2}-3.22 \times 10^{2} \mathrm{CFU} / \mathrm{m}^{3}\right)$ in comparison with a control panel of locations complying with the requirements for Environment, Health and Safety (EHS) (low humidity, presence of an air-conditioning units) [19]. In similar studies designed to evaluate microbiological air evaluation on university premises, Skowron et al. showed the presence of yeasts and filamentous fungi at the level of $10^{1}-10^{2} \mathrm{CFU} / \mathrm{m}^{3}[20]$.

Due to the lack of globally accepted criteria of evaluation of biological agents exposure in the workplace, as well as commonly implemented standard values, the criteria proposed by Górny (2004) $\left(>2 \times 10^{2}-5 \times 10^{2} \mathrm{CFU} / \mathrm{m}^{3}\right)$ may be adopted in interpreting the obtained results, including the total fungi counts in enclosed spaces [20,21]. In the light of these criteria the status of microbiological contamination in examined ambulances as well as in the office spaces has been highly satisfactory. In normal conditions the main source of fungal bioaerosol in the air of confined spaces (offices, etc.) is aerosol migrating from the external environment. The phenomenon becomes particularly relevant in summer and autumn, when the concentrations of fungal spores in the atmospheric air increase. As this study was conducted in winter period, the level of fungal contamination did not reach critical values [22].

In the study, detected non-fermenting Gram-negative bacilli - Acinetobacter spp. and filamentous fungi (according to the list of harmful biological agents) [23], as well as a wide spectrum of coagulase-negative Staphylococci (CoNS), presented various antimicrobial resistance phenotypes.

The level of bacterial and fungal contamination in ambulances varies widely from 0 to $3.0 \times 10^{2} \mathrm{CFU} / 25 \mathrm{~cm}^{2}$, which is similar to the level of microbiological contamination of office surfaces. The exceptions are ambulance floors where much higher concentrations of microorganisms have been observed. This situation may signal the need to implement appropriate procedures of disinfection, decontamination and cleaning of ambulance floors. Nigam and Cutter demonstrated the effectiveness of routine washing and disinfection of the ambulance interiors and equipment used by medical services $[24,25]$. In several related studies $[18,25,26]$ similar levels of microbiological contamination of internal ambulance surfaces were found. In contrast to these results, in the study of Alves and Bissell, the contamination of ambulance equipment, instruments and accessories in ambulances was 100 times higher $\left(0-1.0 \times 10^{2} \mathrm{CFU} / \mathrm{mm}^{2}\right)$ [10].

The quality analysis of imprints and swab samples collected from ambulances showed the presence of environmental flora such as Bacillus spp., S. paucimobilis, K. roseae, Rhizobium spp., S. plymuthica, G. sulfidifaciens, 
L. adecarboxylata, $A$. viridans and also potentially pathogenic coagulase-negative Staphylococci (3.8\%) presenting efflux pump system (macrolides and streptogramin B resistance $-\mathrm{MS}_{\mathrm{B}}$ ), constitutive macrolide, lincosamide and streptogramin $\mathrm{B}\left(\mathrm{MLS}_{\mathrm{B}}\right)$ and methiciline resistance coagulase-negative Staphylococci) (MRCNS) - S. heamolyticus (a swab from a medical equipment) and $1.8 \%$ nonfermentative Gram-negative bacilli - Acinetobacter spp. with multidrug resistance. In one location (a wall imprint) the MRSA (alert-pathogen), additionally resistant to erythromycin, clindamycin (constitutive $\mathrm{MLS}_{\mathrm{B}}$ ) and tetracycline was also identified.

The microbiological qualitative analysis of ambulance surfaces demonstrated similarity to the results of other authors who isolated P. aeruginosa, E. faecalis, S. epidermidis, Bacillus spp., S. haemolyticus, Pantoea agglomerans [10,27]. Other studies of microbiological content of work surfaces, accessories and medical equipment in ambulances showed a wide spectrum of microorganisms, from environmental flora to potentially pathogenic non-fermentative Gram-negative bacilli (15.1\%) with the prevalence of Pseudomonas spp. and Acinetobacter spp.; MRSA and MRCNS 0.9\% and K. pneumoniae $(0.5 \%)$ were also found [28]. Vikke and Giebner conducted an interesting examination of ambulance crew uniforms; the study showed contamination with potentially pathogenic bacteria, such as Bacillus cereus (27.78\%), Clostridium spp., Enterococcus spp. (2.22\%) and S. aureus (21.11\%) [25]. Similar profile of microorganisms was revealed by Nigam and Cutter in the swab analysis of work spaces and medical instruments. In this case, the most widespread microorganisms were: coliforms (31.5\%), S. epidermidis (29.4\%) and Bacillus spp. (21.9\%) [24]. Luksamijarulkul and Pipitsangjan presented a similar microbiological profile in the analysis of surfaces in ambulances Staphylococcus spp. (47\%), Gram-negative bacilli (32\%), Grampositive bacilli (12\%) [18].
The mycological analysis revealed the presence of various species of pathogenic as well as non-pathogenic fungi. Existing Aspergillus spp. included following species: A. niger, A. fumigatus, $A$. versicolor and Penicillium spp. presented by $P$. expansum and $P$. citrinum. A similar mycological profile was observed by Noh et al. and Luksamijarulkul and Pipitsangjan [18,28].

Apart from ubiquitous saprophytic species such as T. koningii, C. globosum and U. atrum air samples from ambulances and offices contained other, potentially dangerous, species which may cause allergies, infections or toxic reactions to mycotoxins $[19,29,30]$. The mycological analysis of air and surface samples from ambulances and offices mainly showed the presence of Aspergillus and Penicillium genera. However, these genera occurred commonly in atmospheric air, the presence of them at the workplaces may constitute potential hazards to employees (group 2 according to their level of risk of infection and allergy) [23]. Fungal quality assessment of examined workplaces is similar to results obtained by other researchers [18,31-33].

Pathogenic $A$. fumigatus was found in swab samples from an office keyboard and an ambulance ventilation system. This species is the main etiologic agent of pulmonary and systemic aspergillosis in immunocompromised persons. It may occur as an opportunistic pathogen or as an allergen, moreover, it is found on the list of harmful biological agents found in the workplace [23,34-36].

However, only exposure to high levels of airborne filamentous fungi (e.g., $10^{10}$ spores $/ \mathrm{m}^{3}$ ) associated with bioaerosols may result in sickness partly caused by mycotoxins [37]. Further to this, the number of fungi in our research has not exceeded the designated level.

In this study, the level of microbiological contamination in the ambulance workplaces does not create a potential health threat to medical personnel and patients, as well. However, the presence of potentially pathogenic biological agents in the ambulances may be the source of 
transmission to patients and ambulance personnel. Due to exposure to potentially dangerous biological agents, the personnel of the Emergency Medical Services requires special health and safety procedures. The implementation of procedures preventing microbial transmission and interrupting transmission routes may increase occupational safety in ambulance environment.

\section{CONCLUSIONS}

The level of microbiological contamination in ambulances was satisfactory and within accepted range as well as comparable with office spaces without putative occupational exposure to biological agents. This may be an evidence of the effectiveness of existing cleaning and disinfection procedures. However, the presence of potentially pathogenic microorganisms, including alert-pathogens (MRSA, Aspergillus spp.) and toxynogenic fungi, in ambulances is a threat to the health of medical personnel and patients if their infectious doses would be reached. The predominant isolated bacteria and fungi in air samples were Staphylococcus spp. and Aspergillus spp., respectively.

\section{REFERENCES}

1. Eveillard M, Quenon JL, Rufat P, Mangeol A, Fauvelle F. Association between hospital-acquired infections andpatients' transfers. Infect Control Hosp Epidemiol. 2001;22:693-6, https://doi.org/10.1086/501847.

2. Krogulski A. [Hospitals locations and indor airmicrobiological quality]. Roczn Panstw Zakl Hig. 2008;59(1):97-102. Polish.

3. Makarowski T, Krajewska-Kułak E, Łukaszuk C, Gniadek A, Macura AB, Sobolewski M, et al. [Analysis of air contamination with fungi at Radiology Department in Białystok]. Med Mycol. 2009;16(3):148-54. Polish.

4. Steinka I. [The role of abiogenic factors in the transmission of microflora in hospital settings]. Ann Acad Med Gedan. 2013;43:165-74. Polish.
5. Ogórek R, Kalinowska K, Pląskowska E, Baran E, Matkowski K. [Air contamination of fungi in various culture media in selected rooms of Dermatology Clinic, part II]. Mikrob Lek. 2011;18(2):79-86. Polish.

6. National Sanitary Inspectorate. [Country sanitary conditions report, 2009]. Warszawa: The Inspectorate; 2009. Polish.

7. National Sanitary Inspectorate. [Country sanitary conditions report, 2010]. Warszawa: The Inspectorate; 2010. Polish.

8. National Sanitary Inspectorate. [Country sanitary conditions report, 2011]. Warszawa: The Inspectorate; 2011. Polish.

9. Hajduga MA, Węgrzynkiewicz S, Sołek D, Jędrzejczyk D, Hajduga M. [Bacterial pathogens in ambulances as possible danger]. Aktual Probl Biomech. 2013;7:69-74. Polish.

10. Alves DW, Bissell RA. Bacterial pathogens in ambulances: Results of unannounced sample collection. Preliminary reports. Prehosp Emerg Care. 2008;12:218-24, https://doi. org/10.1080/10903120801906721.

11. European Committee on Antimicrobial Susceptibility Testing [Internet]. Copenhagen: The Committee; 2016 [cited 2016 May 9]. Clinical breakpoints. Available from: http:// www.eucast.org/clinical_breakpoints.

12. Domsch KH, Gams W, Anderson TH. Compendium of soil fungi. Vol. 1. No. 2. London: Academic Press; 1980.

13. Barnett HL, Hunter BB. Illustrated genera of imperfect fungi. St. Paul (MN): American Phytopathological Society Press; 1998.

14. Index Fungorum [Internet]. Index Fungorum Partnership; 2016 [cited 2016 May 9]. Names. Available from: http://www. indexfungorum.org/names/names.asp.

15. Luksamijarulkul P, Pipitsangjan S. Vatanasomboon P. Occupational risk towards blood-borne infections among ambulance personnel in a provincial hospital network in Thailand. Southeast Asian J Trop Med Public Health. 2014; 45(4):940-8.

16. Speers D. Infectious diseases and the pre-hospital practitioner. J Emerg Prim Health Care. 2003;1(1):1-9.

17. Mahomed O, Jinabhai CC, Taylor M, Yancey A. The preparedness of emergency medical services against occupa- 
tionally acquires communicable diseases in the prehospital environment in South Africa. Emerg Med J. 2007;24(7):497500, https://doi.org/10.1136/emj.2006.045575.

18. Luksamijarulkul P, Pipitsangjan S. Microbial air quality and bacterial surface contamination in ambulances during patient service. Oman Med J. 2015;30(2):104-10, https://doi. org/10.5001/omj.2015.23.

19. Buczyńska A, Cyprowski M, Piotrowska A, SzadkowskaStańczyk I. [Filamentus fungi in the air of offices - The results of environmental intervention]. Med Pr. 2007;58(6):521-5. Polish.

20. Skowron K, Kaczmarek A, Budzyńska A, Gospodarek E. [Microbiological quality of indoor air university]. Ekol Tech. 2014;22(4):155-64. Polish.

21. Górny RL. [Biohazards: Standard recommendations and proposals of the limit values]. Podst Met Oceny Środ Pr. 2004;3(41):17-39. Polish.

22. Lis DO, Pastuszka JS, Górny RL. [The prevalence of bacterial and fungal aerosol inside and outside of homes and offices in Upper Silesia. Preliminary results]. Rocz Panstw Zakl Hig. 1997;48(1):59-68. Polish.

23. [Regulation of Polish Ministry of Health, 23rd December 2011 regarding alert pathogens, hospital acquired registry and actual epidemiological hospital situation]. J Laws 2011, No. 294, item 1741. Polish.

24. Nigam Y, Cutter J. A preliminary investigation into bacterial contamination of welsh emergency ambulances. Emerg Med J. 2003;20:479-82, https://doi.org/10.1136/emj. 20.5.479.

25. Vikke HS, Giebner M. UniStatus - A cross-sectional study on the contamination of uniforms in the Danish ambulance service. BMC Res Notes. 2015;8:95, https://doi.org/10.1186/ s13104-015-1057-4.

26. Eibicht SJ, Vogel U. Meticillin-resistant Staphylococcus aureus (MRSA) contamination of ambulance cars after short term transport of MRSA-colonised patients is restricted to the stretcher. J Hosp Infect. 2011;78:221-5, https://doi. org/10.1016/j.jhin.2011.01.015.
27. Hajduga M, Hajduga MA, Jędrzejczyk D, Bułdak R, Sotek D. [An ambulance as the habitant of fungi]. Aktual Probl Biomech. 2014;8:39-44. Polish.

28. Noh H, Shin SD, Kim NJ, Ro YS, Oh HS, Joo SI, et al. Risk stratification-based surveillance of bacterial contamination in metropolitan ambulances. J Korean Med Sci. 2011;26:124-30, https://doi.org/10.3346/jkms.2011.26.1.124.

29. Beasley VR. Trichothecene mycotoxicosis: Pathophysiologic effects. Boca Raton (FL): CRC Press Inc.; 1989.

30. Charkowska A, Bogdan A. [Ventilation and air-conditioning ducts - Cleaning and disinfection methods]. Bezpiecz Pr. 2008;10:16-7. Polish.

31. Górny RL, Harkawy AS, Ławniczek-Wałczyk A, Karbowska-Berent J, Wlazło A, Niesler A, et al. Exposure to culturable and total microbiota in cultural heritage conservation laboratories. Int J Occup Med Environ Health. 2016;29(2): 255-75, https://doi.org/10.13075/ijomeh.1896.00630.

32. Gołofit-Szymczak M, Górny R, Ławniczek-Wałczyk A, Cyprowski M, Stobnicka A. [Bacterial and fungal aerosols in the work environment of cleaners]. Med Pr. 2015;66(6): 779-91, https://doi.org/10.13075/mp.5893.00349. Polish.

33. Harkawy A, Górny RL, Ogierman L, Wlazło A, ŁawniczekWałczyk A, Niesler A. Bioaerosol assessment in naturally ventilated historical library building with restricted personnel access. Ann Agric Environ Med. 2011;18(2):323-9.

34. Slesiona S, Gressler M, Mihlan M, Zaehle C, Schaller M, Barz D, et al. Persistence versus escape: Aspergillus terreus and Aspergillus fumigatus employ different strategies during interactions with macrophages. PLOS One. 2012;7(2): e31223, https://doi.org/10.1371/journal.pone.0031223.

35. Pląskowska E, Korol M, Ogórek R. Fungi found in air-conditioned room. Part II. Mikol Lek. 2012;19(1):27-36.

36. Rhodes JC, Jensen HE, Nilius AM, Chitambar CR, Farmer SG, Washburn RG, et al. Aspergillus and aspergillosis. J Med Vet Mycol. 1992;30(Suppl 1):51-7, https://doi. org $/ 10.1080 / 02681219280000761$.

37. Robbins CA, Swenson LJ, Nealley ML, Gots RE, Kelman BJ. Health effects of mycotoxins in indoor air: A cri- 
tical review. J Occup Environ Hyg. 2000;15(10):773-84, https://doi.org/10.1080/10473220050129419.

38. Chwala K, Vishwanath S, Munim FC. Nonfermenting gramnegative bacilli other than Pseudomonas aeruginosa and
Acinetobacter spp. causing respiratory track infections in a tertiary care center. J Glob Infect Dis. 2013;5(4):144-8, https://doi.org/10.4103/0974-777X.121996.

This work is available in Open Access model and licensed under a Creative Commons Attribution-NonCommercial 3.0 Poland License - http://creativecommons.org/ licenses/by-nc/3.0/pl/deed.en. 